\title{
Fabrication of broadband antireflective sub-wavelength structures on fluorescent SiC
}

Ou, Yiyu; Jokubavicus, V.; Kaiser, M.; Wellmann, P.; Linnarsson, M. K.; Yakimova, R.; Syväjärvi, M.; Ou, Haiyan

Publication date:

2012

Link back to DTU Orbit

Citation (APA):

Ou, Y., Jokubavicus, V., Kaiser, M., Wellmann, P., Linnarsson, M. K., Yakimova, R., Syväjärvi, M., \& Ou, H. (2012). Fabrication of broadband antireflective sub-wavelength structures on fluorescent SiC. Abstract from European Conference on Silicon Carbide and Related Materials (ECSCRM 2012), Saint-Petersburg, Russian Federation.

\section{General rights}

Copyright and moral rights for the publications made accessible in the public portal are retained by the authors and/or other copyright owners and it is a condition of accessing publications that users recognise and abide by the legal requirements associated with these rights.

- Users may download and print one copy of any publication from the public portal for the purpose of private study or research.

- You may not further distribute the material or use it for any profit-making activity or commercial gain

- You may freely distribute the URL identifying the publication in the public portal

If you believe that this document breaches copyright please contact us providing details, and we will remove access to the work immediately and investigate your claim 


\title{
Fabrication of broadband antireflective sub-wavelength structures on fluorescent SiC
}

\author{
$\underline{Y . ~ O u}^{a}$, V. Jokubavicius ${ }^{b}$, M. Kaiser ${ }^{c}$, P. Wellmann ${ }^{c}$, M. K. Linnarsson ${ }^{d}$, R. \\ Yakimova $^{b}, M$. Syväjärvi ${ }^{b}$, and $\mathrm{H}$. Ou ${ }^{a}$ \\ Email: yiyo@fotonik.dtu.dk \\ ${ }^{a}$ Department of Photonics Engineering, Technical University of Denmark, DK-2800, \\ Lyngby, Denmark \\ ${ }^{\mathrm{b}}$ Department of Physics, Chemistry and Biology, Linköping University, SE-58183, \\ Linköping, Sweden \\ ${ }^{\mathrm{c}}$ Materials of Electronics and Energy Technology, University of Erlangen-Nuremberg, \\ D-91058, Erlangen, Germany \\ ${ }^{d}$ School of Information and Communication Technology, KTH Royal Institute of \\ Technology, SE-16440, Kista, Sweden
}

Nitrogen ( $\mathrm{N}$ ) and boron (B) doped $6 \mathrm{H}-\mathrm{SiC}$ has been proven as a high-efficiency wavelength converter material in white light-emitting diodes (LEDs) [1, 2]. The light extraction efficiency of semiconductor LEDs is usually low due to the internal reflection loss. In this work, we obtained broadband surface antireflection and omnidirectional light enhancement on fluorescent $6 \mathrm{H}$-SiC by fabricating antireflective sub-wavelength structures (ARS).

To fabricate the ARS on SiC, a positive photoresist layer was first spin-coated on the $6 \mathrm{H}$-SiC sample and then prebaked on a hot plate at $160^{\circ} \mathrm{C}$ for 2 minutes. The designed mask pattern was transferred to the photoresist coating by applying the ebeam lithography. After the development, a hard mask layer was deposited on the patterned photoresist using the e-beam evaporation with a subsequent lift-off process. The dot-shaped pattern was then obtained on the hard mask. The dry etching process using $\mathrm{SF}_{6}$ and $\mathrm{O}_{2}$ precursors was carried out in the reactive-ion etching system and the etch conditions were well optimized. Finally, the cone-shaped ARS with designed configuration (bottom diameter of $250 \mathrm{~nm}$, pitch of $350 \mathrm{~nm}$, and height of $1.4 \mu \mathrm{m}$ ) were formed on the SiC surface. An oblique-view scanning electron microscope (SEM) image of the ARS pattern is shown in the inset of Fig. 1(a).

The surface reflectance of the bare and ARS SiC samples were measured by a goniometer system at a measured angle of 6 degrees, where 0 degree is the direction normal to the sample surface. The reflectance spectra were measured from 390 to $785 \mathrm{~nm}$ which covers the entire visible spectral range (typically from 390 to $750 \mathrm{~nm}$ ) and the results are shown in Fig. 1(a). It is seen that the surface reflection is effectively suppressed by applying the SiC ARS. The average reflectance over the measured spectral range decreased from $20.5 \%$ to $1.0 \%$ and the minimum reflectance close to 0 was observed at around $400 \mathrm{~nm}$ for the ARS SiC sample. Although the reflectance starts to increase at above $680 \mathrm{~nm}$, the reflectance over the entire visible spectral range is below $2 \%$. This result suggests that the SiC ARS is an effective way to suppress the surface reflection for the fluorescent SiC sample in the whole visible spectral range. 
The angle-resolved photoluminescence spectra of the SiC samples with and without the ARS were also acquired by the same goniometer system. A $377 \mathrm{~nm}$ diode laser was used as excitation source which was normal to the sample backside and the detected emission angle varied from 16 to 80 degrees. Fig. 1(b) shows the spatial emission patterns for both samples, one can see that the luminescence intensity increased at all emission angles with a well preserved spatial emission pattern. It is also found that the luminescence intensity was enhanced by more than $91 \%$ in a very large emission angle range (up to 70 degree). From Fig. 1(c), it is seen that the luminescence intensity of the bare SiC decreases together with a blue shift of the peak wavelength as the emission angle increases from 20 to 70 degree, which could be attributed to the Fabry-Pérot microcavity interference effect. In Fig. 1 (d), although the luminescence intensity of the ARS SiC also decreases with larger emission angle, the peak wavelength remains the same which is due to the elimination of the Fabry-Pérot microcavity interference effect by introducing the ARS on the SiC surface.

In conclusion, fabrication of antireflective sub-wavelength structures on fluorescent $\mathrm{SiC}$ is an effective way to suppress the surface reflection over the entire visible spectral range and achieve the omnidirectional light enhancement.

\section{References}

[1] S. Kamiyama, et al., J. Appl. Phys. 99, 093108 (2006).

[2] Y. Ou, et al., Opt. Mater. Express 1, 1439-1446 (2011).

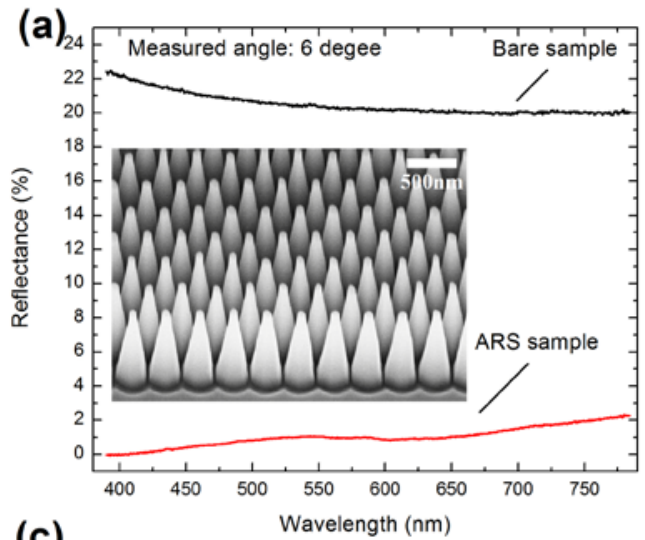

(b)
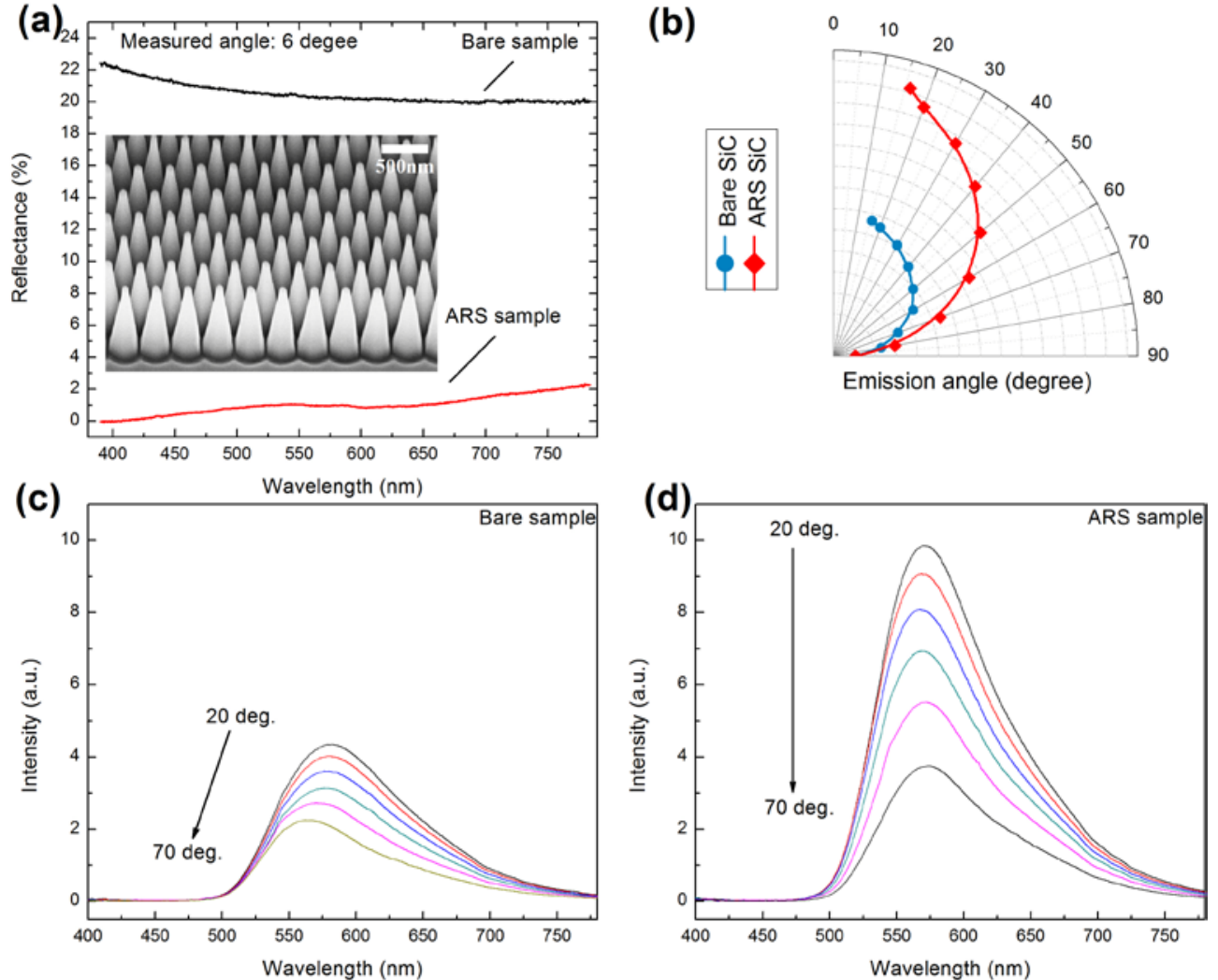

Fig. 1: (a) Surface reflectance (inset: SEM figure of fabricated ARS on SiC); (b) spatial emission pattern; angle-resolved photoluminescence of (c) bare and (d) ARS $\mathrm{SiC}$ samples. 